\title{
Geographic influence on postoperative complications in children with complicated appendicitis: a single center study
}

\author{
Mohammad Seqsaqa ${ }^{*^{*}}$ D, Ahmed Ezzat Rozeik', Mohammed Khalifa ${ }^{1}$ and Hazem Nour Abdellatif Ashri
}

\begin{abstract}
Background: Acute appendicitis is one of the most common abdominal emergencies in children. Complicated appendicitis is much more common in pediatric age group than in adults due to probability of delay in diagnosis or misdiagnosis. Geographic status has an influence on the clinical course of such surgical cases. This prospective comparative study was conducted at the pediatric surgery department in our hospital in Egypt during the period from December 2018 to August 2019, aiming to find the relation between residence of patients and occurrence of post-operative complications among patients in Sharkia Governorate, Egypt. Patients were divided into two groups: rural and urban. Data recorded included demographic data, preoperative assessment, operative findings, postoperative course, postoperative complications, and follow-up.

Results: Sixty patients were included in the study, 32 of them were from rural areas, and 28 were from urban areas. There was no significant difference between them regarding demographics. Duration of symptoms was significantly longer with rural group ( $3.7 \pm 1.4$ vs. $3.07 \pm 0.92$ days). Length of hospital stay was significantly longer with the rural group ( $4.7 \pm 1.7$ vs. $4.7 \pm 1.7$ days). The rate of wound infection was significantly higher with the rural group (34.37\% vs. 10.7\%), while other postoperative complications were increased with rural group, but that was not statistically significant. The regularity of follow-up was higher with the urban group.

Conclusions: Children with complicated appendicitis from rural areas are at higher risk for occurrence of postoperative complications and poor outcome, with less regularity in follow-up. This is because of many obstacles they faced, including difficulties of transportation, insufficient medical services, and low socioeconomic and educational statuses.
\end{abstract}

Keywords: Complicated appendicitis, Children, Urban, Rural, Postoperative

\section{Background}

Geographic status usually has an impact on the personal health. This impact becomes more obvious in case of medical and surgical emergencies [1]. Patients from rural areas were considered to be at a higher risk for medical and surgical complications than that from urban areas, especially in the developing countries [2]. This is due to the

\footnotetext{
* Correspondence: mseqsaqa@gmail.com

Reprints will not be available from the authors.

'Pediatric Surgery Department, Faculty of Medicine, Zagazig University

Hospitals, Zagazig University, Zagazig 44519, Egypt

Full list of author information is available at the end of the article
}

delay in seeking medical advice, thus delaying in management as well, which results in undesirable outcomes [1].

Acute appendicitis is one of the most common abdominal conditions requiring surgery in pediatric age group. Delay of presentation is an important factor in occurrence of complicated appendicitis [3]. If not treated or managed carefully, acute appendicitis usually takes no more than $36 \mathrm{~h}$ to perforate, while appendicular abscess usually needs more than 2-3 days to occur [4].

Lack of access to an appropriate healthcare unit and misdiagnosing of non-surgical conditions are substantial factors for higher rate of complicated appendicitis in rural than urban areas $[5,6]$. 
The most popular problems in rural areas include low income and education levels, shortage in physicians and medical resources, travel distances, and transportation obstacles $[2,7,8]$.

The geographic influence shows also an effect on postoperative complications, which were noticed to be increased with rural patients that received the medical care in the same hospital as urban patients $[9,10]$.

The purpose of this study is to determine the effect of geographic status on the postoperative complications in children with complicated appendicitis in Sharkia Governorate, Egypt. We hypothesized that the outcome of complicated appendicitis in children will be better in urban than rural patients, with decreasing in the rate of postoperative complications.

\section{Methods}

This prospective comparative study was conducted at the pediatric surgery department in our hospital, during the period from December 2018 to August 2019. During the period of study, 60 patients were diagnosed and operated for complicated appendicitis based on history, clinical examination, laboratory findings, and ultrasonography. Patients with simple appendicitis or more than 12 years old were excluded. Written informed consent was obtained from all parents.

Complicated appendicitis in this study was defined as acute appendicitis in which perforation with purulence or fecalith in the abdominal cavity or gangrenous appendicitis with or without intraabdominal abscess.

Data was collected regarding demographics, preoperative assessment, intraoperative findings, operative time, length of hospital stay, time taken to start oral intake, and occurrence of postoperative complications, including wound infection, intraperitoneal collection, ileus, and readmission.

All patients had general endotracheal anesthesia and muscle relaxant. A Foley's catheter and a nasogastric tube were used when indicated. All cases were managed with laparoscopic appendectomy using a two-handed, three trocar technique.

The operative time in this study was measured as the real time of operation, from the first skin incision to the last skin closure with exclusion of the time of anesthesia and preparation.

All patients received intravenous antibiotics (cefotaxime (a third generation cephalosporin, $100 \mathrm{mg} / \mathrm{kg} /$ day), metronidazole $(7.5 \mathrm{mg} / \mathrm{kg} / \mathrm{q} 8 \mathrm{~h}$ ), and analgesia (paraceta$\mathrm{mol}, 15 \mathrm{mg} / \mathrm{kg} / \mathrm{q} 6 \mathrm{~h})$ ). When the bowel function was restored, oral intake was started as soon as patients could tolerate it. Drain was removed usually after $48-72 \mathrm{~h}$ if there was no discharge and the abdomen of patient was lax and not distended. Patients were discharged after remaining afebrile for $24 \mathrm{~h}$ and after they can tolerate normal diet and exhibited a decrease in the white blood cell count to the normal level. The patients were followed up in the outpatient clinic at 1-week, 2-week, 3 -week, and at 1-month intervals for 3 months as a usual role of our clinic. Follow-up of the patients included ensuring normal bowel habits and daily activity or occurrence of postoperative complications that included wound infection, intraabdominal abscess, occurrence of ileus, and readmission. Wound infection was defined as purulent discharge from the incision and growth of microorganisms from the wound discharge.

The collected data was analyzed using the software SPSS version 20. Quantitative variables were described using their means and standard deviations. Categorical variables were described using their absolute frequencies and were compared using Chi square test and Fisher exact test when appropriate. Independent sample $t$ test (used with normally distributed data) was used to compare means of two groups. The level of statistical significance was set at $5 \%(p<0.05)$. Highly significant difference was present if $p \leq 0.001$. This study was approved by the Institutional Review Board (ZU-IRB \#4787/5-8-2018), registered 5 August 2018.

\section{Results}

A total of 60 patients were included in the study, 32 of them were from rural areas, and 28 were from urban areas. Personal characteristics showed no significant difference between the two groups. There was no significant difference between the two groups regarding preoperative total leukocytic count (TLC) and ultrasonographic features, but the duration of symptoms was significantly longer with rural patients (Table 1).

There was no significant difference between the two groups regarding intraoperative findings, operative time, or the time taken to regain oral intake, while the length of hospital stay was significantly longer with rural patients. There was one case that was converted from laparoscopic to open appendectomy in each group; the case in rural group was converted due to extensive adhesions, and that in the urban group had a perforation close to the cecum (Table 2).

There was an increased rate of wound infection among rural group, which was statistically significant. Although other postoperative complications were increased in the rural group; interestingly, the difference was not statistically significant. The regularity of follow-up was achieved by attending at least five out of the six planned appointments. The regularity achievement was significantly higher with the urban group (Table 3).

\section{Discussion}

Geographic status has a considerable effect on the different surgical situations, either on the preoperative or the postoperative courses $[2,8]$. 
Table 1 Personal characteristics and preoperative assessment

\begin{tabular}{|c|c|c|c|c|}
\hline \multirow{3}{*}{$\begin{array}{l}\text { Demographic characteristics } \\
\text { and preoperative assessment }\end{array}$} & \multicolumn{2}{|l|}{ Groups } & \multicolumn{2}{|l|}{ Test } \\
\hline & Rural & Urban & $\mathrm{x}^{2} / t$ & $p$ \\
\hline & $N=32(\%)$ & $N=28(\%)$ & & \\
\hline \multicolumn{5}{|l|}{ Gender } \\
\hline Male & $20(62.5)$ & $16(57.14)$ & 0.18 & 0.67 \\
\hline Female & $12(37.5)$ & $12(42.86)$ & & \\
\hline \multicolumn{5}{|l|}{ Age (years) } \\
\hline Mean \pm SD & $9.34 \pm 1.68$ & $8.93 \pm 2.23$ & 0.81 & 0.42 \\
\hline Range & $7-12$ & $5-12$ & & \\
\hline \multicolumn{5}{|l|}{ Body mass index } \\
\hline Mean \pm SD & $22.23 \pm 3.15$ & $24.13 \pm 4.14$ & 1.94 & 0.057 \\
\hline Range & $17.5-28$ & $18-32$ & & \\
\hline \multicolumn{5}{|l|}{ Duration of symptoms } \\
\hline Mean \pm SD & $3.7 \pm 1.4$ & $3.07 \pm 0.92$ & 2.03 & $0.047^{*}$ \\
\hline Range & $2-7$ & $2-5$ & & \\
\hline \multicolumn{5}{|l|}{$\operatorname{TLC}\left(10^{3} / \mathrm{mm}^{3}\right)$} \\
\hline Mean \pm SD & $16.52 \pm 2.43$ & $16.91 \pm 2.8$ & 0.58 & 0.57 \\
\hline Range & $12.6-20.7$ & $13-22$ & & \\
\hline +ve ultrasonographic findings & $28(87.5)$ & $24(85.7)$ & 0.04 & 0.84 \\
\hline
\end{tabular}

$p>0.05$ is statistically non-significant

$x^{2}$ Chi square test, $t$ independent sample $t$ test

Appendicitis is one of the most common surgical situations affecting children. The risk of complications is higher in this age group than in adults $[5,11]$.

Children have difficulties in understanding and expressing their complaints, and therefore more commonly present with perforation. Also, the delay in seeking medical advice and misdiagnosing with similar medical conditions are apparent causes that increase the risk of complications $[3,12]$.

Table 2 Operative details and postoperative course

\begin{tabular}{|c|c|c|c|c|}
\hline \multirow{3}{*}{$\begin{array}{l}\text { Operative details and } \\
\text { postoperative course }\end{array}$} & \multicolumn{2}{|l|}{ Groups } & \multicolumn{2}{|l|}{ Test } \\
\hline & Rural & Urban & $\overline{x^{2} / t}$ & $p$ \\
\hline & $N=32(\%)$ & $N=28(\%)$ & & \\
\hline Pathological appearance & & & 0.44 & 0.804 \\
\hline Gangrenous & $10(31.25)$ & $9(32.15)$ & & \\
\hline Perforated & $16(50)$ & $12(42.85)$ & & \\
\hline Suppurative & $6(18.75)$ & $7(25)$ & & \\
\hline Operative time (min) & & & 0.14 & 0.89 \\
\hline Mean \pm SD & $85.63 \pm 28.1$ & $84.64 \pm 26.78$ & & \\
\hline Range & $55-150$ & $45-140$ & & \\
\hline Regain of fluid intake (days) & & & 1.6 & 0.113 \\
\hline Mean \pm SD & $2.14 \pm 0.7$ & $1.87 \pm 0.6$ & & \\
\hline Range & $1-3$ & $1-3$ & & \\
\hline Hospital stay (days) & & & 2.16 & $0.035^{*}$ \\
\hline Mean \pm SD & $4.7 \pm 1.7$ & $3.8 \pm 1.5$ & & \\
\hline Range & $2-8$ & $2-7$ & & \\
\hline
\end{tabular}


Table 3 Postoperative complications and follow-up

\begin{tabular}{|c|c|c|c|c|}
\hline \multirow{3}{*}{$\begin{array}{l}\text { Postoperative } \\
\text { complications and } \\
\text { follow-up }\end{array}$} & \multicolumn{2}{|l|}{ Groups } & \multicolumn{2}{|l|}{ Test } \\
\hline & Rural & Urban & $x^{2} / t$ & $p$ \\
\hline & $N=32(\%)$ & $N=28(\%)$ & & \\
\hline Wound infection & $11(34.37)$ & $3(10.7)$ & 4.67 & $0.03^{*}$ \\
\hline Intraperitoneal collection & $2(6.25)$ & $1(3.57)$ & 0.225 & 0.36 \\
\hline lleus & $2(6.25)$ & $0(0)$ & 1.8 & 0.178 \\
\hline Readmission & $2(6.25)$ & $1(3.57)$ & 0.225 & 0.36 \\
\hline Follow up regularity & $19(59.4)$ & $24(85.7)$ & 5.1 & $0.024 *$ \\
\hline
\end{tabular}

$p>0.05$ is statistically non-significant

$x^{2}$ Chi square test, $t$ independent sample $t$ test

Therefore, patients in rural areas are more susceptible for developing complications due to their socioeconomic status that results in delaying management of such cases $[2,10,13]$.

While most of the published data discussed to date have focused on the effect of residency on the cases before or at the time of diagnosis and management $[1,2,6$, 10, 13-15]. The disease severity and outcome are influenced by the demographic and socioeconomic status from the first moment of contact with the healthcare providers till achieving a complete recovery. So, it is important to study the effect of the geographic status on the postoperative course $[9,14,16]$.

There was a significant delay in attending hospital from the beginning of symptoms in the rural group than the urban group. Almost similar results were reported in the literature as that reported by Kong et al. [16]. This is due to obstacles of transportation from rural areas and difficulties in early diagnosis and management $[1,10]$.

In our study, there is still increase in the rate of perforation in the rural group, but it was not statistically significant. Other literature reported an increased rate of perforation among the rural group $[9,10,16]$. These results vary according to the variety of transportation facilities among different locations.

This study showed that the time taken to start oral intake was slightly increased in the rural group, but it was not statistically significant $(p=0.113)$.

The mean length of hospital stay was longer in the rural group than urban group. Near results were reported by Mcateer et al. (3.8 days in rural group vs. 3.0 days in urban group [9]). Almost similar results were reported also by Lin et al. [15] and Kong et al. [16]. We found that rural patients preferred to be delayed discharged as possible until complete recovery due to lack of medical facilities in their areas, while urban patients preferred to be early discharged as soon as possible as they did not find difficulties in regular follow-up or to come to hospital if any unexpected events may occur.

The higher rate of wound infection recorded in the rural group was nearly similar to that reported by Kong et al. [16]. It could be explained as rural areas are usually characterized by low socioeconomic status and insufficient medical services that result in less postoperative care for cases.

The significant irregularity in follow-up was a noticeable sign in the rural group that could have an effect on the prognosis of cases, especially the care of wound. That could be explained by the lower education, health awareness, and socioeconomic levels among rural areas, in addition to difficulties in transportation facilities.

There were some limitations to this work. One of that was the restricted age of participants to be younger than 12 years old, according to the rules and regulations of our organization. Also, this work was limited to our center which introduce services to a certain governorate; multicentre studies would be needed to have a strong evidence on these results.

\section{Conclusions}

Our study demonstrates that geographic status is a considerable factor that affects the postoperative outcome in children with complicated appendicitis. The delay in seeking medical advice, insufficient medical services, and difficulties in transportation are major factors causing delay of management increasing the risk of complications. Increasing length of hospital stay, rate of wound infection, and lack of follow-up regularity are the most obvious results among rural patients.

\section{Abbreviations \\ TLC: Total leukocytic count}

\section{Acknowledgements}

Not applicable

\section{Authors' contributions}

MS (the corresponding author) collected the data, searched for literature and prepared the manuscript. AER performed the study design and supervised the clinical work. MK performed statistical analysis of the data and reviewed the literature search. HNA performed editing of the manuscript. All authors read and approved the final manuscript.

\section{Funding}

The authors declare that they have not received any funding.

\section{Availability of data and materials}

The datasets used and analyzed during the current study are available from the corresponding author on reasonable request.

\section{Ethics approval and consent to participate}

This article was approved by the Institutional Review Board at Zagazig University (ZU-IRB \#4787/5-8-2018). Written informed consent was obtained from all patients' parents.

Consent for publication

Not applicable.

Competing interests

The authors declare that they have no competing interests. 


\section{Author details}

'Pediatric Surgery Department, Faculty of Medicine, Zagazig University Hospitals, Zagazig University, Zagazig 44519, Egypt. ${ }^{2}$ General Surgery Department, Zagazig University Hospitals, Zagazig, Egypt.

\section{Received: 11 September 2020 Accepted: 11 January 2021}

\section{Published online: 04 February 2021}

\section{References}

1. Lee SL, Shekherdimian S, Chiu VY. Effect of race and socioeconomic status in the treatment of appendicitis in patients with equal health care access. Arch Surg. 2011;146:156-61.

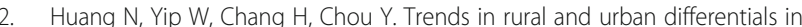
incidence rates for ruptured appendicitis under the National Health Insurance in Taiwan. Public Health. 2006;120:1055-63. https://doi.org/10. 1016/j.puhe.2006.06.011.

3. Brown RL. Appendicitis. In: Ziegler MM, Azizkhan RG, Allmen D, Weber TR, editors. Oper. Pediatr. Surg. 2nd ed., Mc Graw Hill; 2014. p. 613-31.

4. Dunn JCY. Appendicitis. In: Coran AG, editor. Pediatr. Surg. 7th ed., Elsevier Inc; 2012. p. 1255-63.

5. Sullins VF, Lee SL. Appendicitis. In: Holcomb GW, Murphy JP, Ostlie DJ, editors. Ashcraft's Pediatr. Surg. 6th Ed., Elsevier; 2014. p. 568-79.

6. Akhtar-danesh G, Doumouras AG, Flageole H, Hong D. Geographic and socioeconomic predictors of perforated appendicitis: a national Canadian cohort study. J Pediatr Surg. 2019;54:1804-8. https://doi.org/10.1016/j. jpedsurg.2018.10.065

7. Casey MM, Call KT, Klingner JM. Are rural residents less likely to obtain recommended preventive healthcare services? Am J Prev Med. 2001;21: 182-8.

8. Larson SL, Fleishman JA. Rural-urban differences in usual source of care and ambulatory service use analyses of national data using urban influence codes. Med Care. 2003:41:65-74.

9. Mcateer JP, Richards MK, Stergachis A, Abdullah F, Rangel SJ, Oldham KT, et al. Influence of hospital and patient location on early postoperative outcomes after appendectomy and pyloromyotomy. J Pediatr Surg. 2015:50: 1549-55. https://doi.org/10.1016/j.jpedsurg.2015.03.063.

10. Govind SK, Doumouras AG, Nenshi R, et al. Geographic variation in appendiceal perforation rates in Canada: a population-based Cohort Study. J Gastrointest Surg. 2020;24:2620-7. https://doi.org/10.1007/s11605-01904434-3.

11. Ares G, Hunter CJ. History and epidemiology of pediatric appendicitis. In: Hunter CJ, editor. Controv. Pediatr. Append. 1st ed., Springer Nature Switzerland AG; 2019. p. 1-6.

12. Peter SDST, Wester T. Appendicitis. In: GWH III, Murphy JP, Peter SDS, editors. Holcomb Ashcraft's Pediatr. Surg. 7th Ed., China: Elsevier Inc; 2020. p. 664-78

13. Putnam LR, Tsao K, Nguyen HT, Kellagher CM, Lally KP, Austin MT. The impact of socioeconomic status on appendiceal perforation in pediatric appendicitis. J Pediatr. 2016;170:156-60. https://doi.org/10.1016/j.jpeds.2015. 11.075 .

14. Lassiter RL, Hatley RM. Disparities in the management of appendicitis. In: Hunter CJ, editor. Controv. Pediatr. Append. 1st ed., Springer Nature Switzerland AG; 2019. p. 133-43.

15. Lin K, Lai KR, Yang N, Chan C, Liu Y, Pan R. Epidemiology and socioeconomic features of appendicitis in Taiwan: a 12-year populationbased study. World J Emerg Surg. 2015;10:1-13. https://doi.org/10.1186/ s13017-015-0036-3.

16. Kong W, Chb MB, Van De Linde S, Aldous C, Handley JJ, Sa FCA, et al. Quantifying the disparity in outcome between urban and rural patients with acute appendicitis in South Africa. South African Med J. 2013;103:7425. https://doi.org/10.7196/SAMJ.7109.

\section{Publisher's Note}

Springer Nature remains neutral with regard to jurisdictional claims in published maps and institutional affiliations.

\section{Submit your manuscript to a SpringerOpen ${ }^{\circ}$ journal and benefit from:}

- Convenient online submission

- Rigorous peer review

- Open access: articles freely available online

- High visibility within the field

- Retaining the copyright to your article

Submit your next manuscript at $\boldsymbol{\nabla}$ springeropen.com 